\title{
Morphological Characterization of Electrodeposited Zinc-based Matrix Composites
}

\author{
T. Frade, A. Gomes and M. I. da Silva Pereira
}

C.C.M.M., Dep. of Chemistry and Biochemistry, Faculty of Science of the University of Lisbon, Campo Grande Ed. C8, 1749-016 Lisbon, Portugal

Research at the nanometer scale, aiming to create novel materials and devices offering better performance than those of macro/micro systems, is currently of great relevance in many topics of modern science, technology and engineering [1]. In what concerns coatings technology, the nanocomposite films can offer excellent properties in different applications [2,3], representing their morphological characterization a great challenge.

Electrodeposition is widely used for preparing nanocomposite coatings because of its low cost and versatility. Moreover it enables the occlusion of a wide range of nanosized particles into matrices. The nanocomposite characteristics are influenced by the deposition parameters, namely current profile, bath composition, $\mathrm{pH}$, particles concentration and temperature $[4,5]$.

$\mathrm{TiO}_{2}$ nanoparticles are one of the most extensively studied materials because of its remarkable optical and electrical properties, increasing availability, low cost, high chemical stability and their almost environmental photocatalyst behavior. However, there are still a lot of problems needed to be solved in practical applications of $\mathrm{TiO}_{2}$ nanoparticles for photocatalysis. One way to enhance the photocatalytic activity is its use in coating nanocomposite materials, including metal and semiconducting matrices. The coupling two semiconductors provide a novel approach to achieve better corrosion protection and mechanical properties. Additionally, more efficient charge separation, increased lifetime of the charge carriers, and enhanced interfacial charge transfer to adsorbed substrates, are reached $[6,7]$.

The morphological characterization was performed by Scanning Electron Microscopy (SEM) that enabled the high-resolution visualization of the nanocomposite films surface prepared by electrodeposition.

The goal of this work is to show how $\mathrm{TiO}_{2}$ nanoparticles present in nanocomposite films influence the morphology of $\mathrm{Zn}$ (Figure 1) and $\mathrm{ZnO}$ (Figure 2) matrices, to be used as materials in photoelectrocatalysis.

The as-deposited $\mathrm{Zn}-\mathrm{TiO}_{2}$ surface is rougher and more irregular than the $\mathrm{Zn}$ films (Figure 1a and b, respectively). As it can be seen the nanoparticles promote the decrease of matrix grain size. A similar behavior was observed for the $\mathrm{ZnO}$ based nanostructured films (Figure 2). For the $\mathrm{ZnO}$ sample prepared in the absence of $\mathrm{TiO}_{2}$ particles, the formation of arrays of oriented $\mathrm{ZnO}$ nanorods occurs (Figure 2b). Due to the presence of nanoparticles, the film is composed of many flower-like $\mathrm{ZnO}$ agglomerates (Figure 2a and c) made up of numerous hexagonal straight nanorods. The diameter of $\mathrm{ZnO}$ nanorods significantly decreases in the presence of the $\mathrm{TiO}_{2}$ nanoparticles in the bath.

\section{References}

1. Fernandez et al., Analytical and Bioanalytical Chemistry 396 (1): 15-29

2. J.H. Hsieh et al., Thin Solid Films 518 (24): 7263-7266

3. J.M. Yeh et al., Journal of Industrial and Engineering Chemistry 14 (3): 275-291

4. T. Frade et al., Surface and Coatings Technology 204 (21-22): 3592-3598

5. J. Fustes et al., Journal of Solid State Electrochemistry 12 (11): 1435-1443

6. T. Frade et al., Journal of Electrochemical Society 158 (3): C63-C70

7. D. L. Liao et al., Journal of Photochemistry and Photobiology A: Chemistry 194 (1): 11-19 

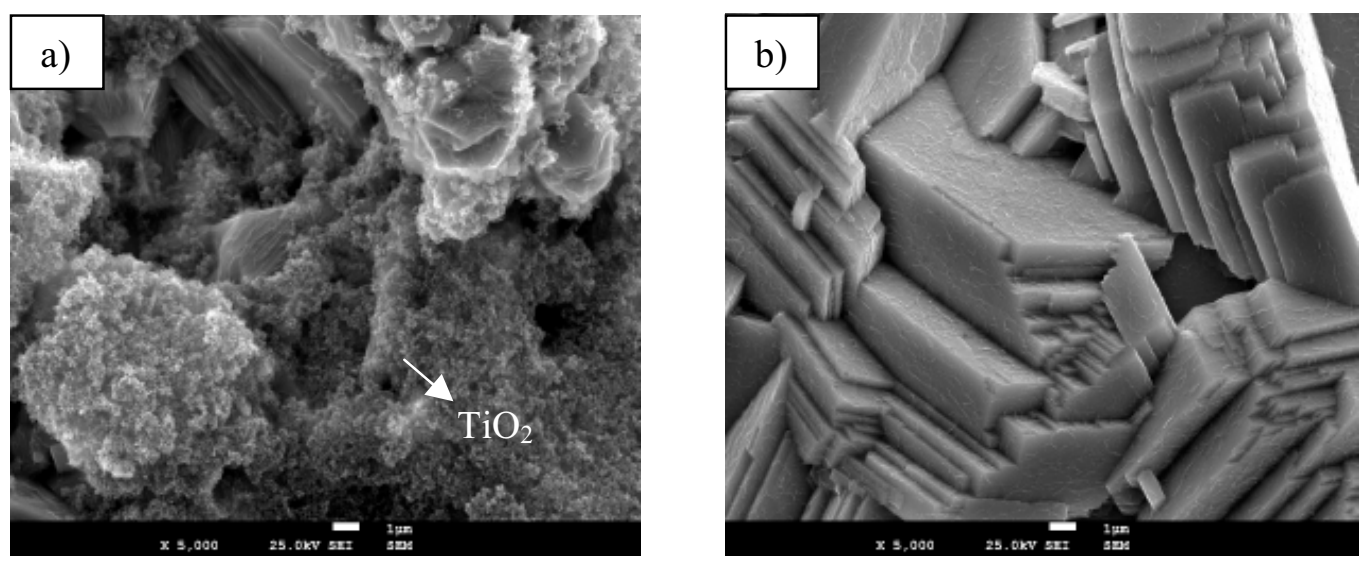

Figure 1. SEM image of $\mathrm{Zn}-\mathrm{TiO}_{2}$ (a) and $\mathrm{Zn}$ (b) prepared by electrodeposition, in steel substrate, from acidic sulphate bath.

\section{a)}
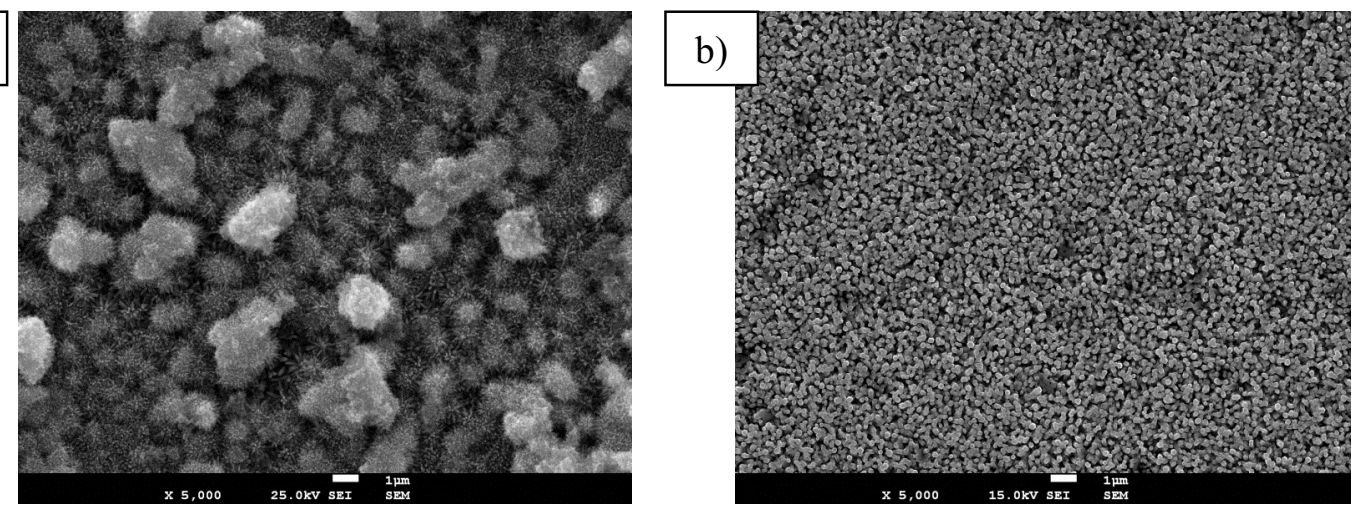

c)

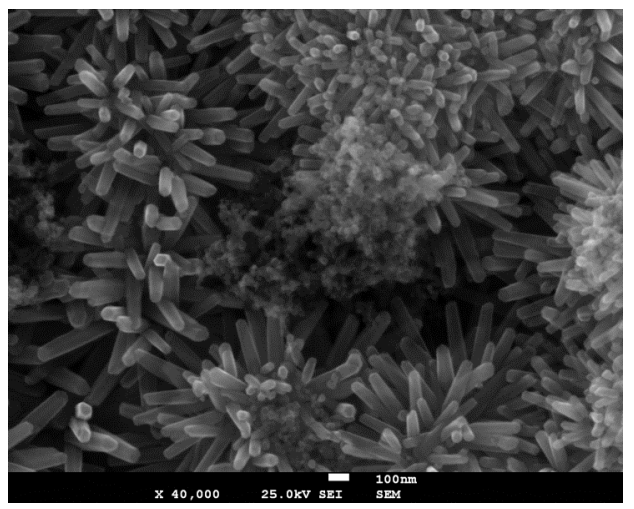

Figure 2. SEM image of $\mathrm{ZnO}-\mathrm{TiO} 2$ (a and c) and $\mathrm{ZnO}$ (b) prepared by electrodeposition in FTO substrate, from zinc nitrate bath. 